\title{
Therapeutic Instruments Targeting Meibomian Gland Dysfunction
}

\author{
Laura Valencia-Nieto (1) - Andrea Novo-Diez (D) - Marta Blanco-Vázquez (1) · \\ Alberto López-Miguel (1)
}

Received: July 16, 2020 / Accepted: September 11, 2020 / Published online: September 24, 2020

(C) The Author(s) 2020

\section{ABSTRACT}

The most prevalent type of meibomian gland dysfunction (MGD), which is obstructive, is the main cause of evaporative dry eye and is characterized by changes in the meibum composition and duct obstruction. Eyelid hygiene has usually been the most common clinical approach. However, alternative therapies for MGD are emerging on the market. Some warming and humidity devices have led to an improvement in the signs and

Laura Valencia-Nieto, Andrea Novo-Diez, and Marta Blanco-Vázquez have contributed equally to this manuscript.

Digital Features To view digital features for this article go to https://doi.org/10.6084/m9.figshare.12937559.

L. Valencia-Nieto $\cdot$ A. Novo-Diez .

M. Blanco-Vázquez · A. López-Miguel

Instituto Universitario de Oftalmobiología Aplicada

(IOBA), Universidad de Valladolid, Valladolid, Spain

A. Novo-Diez

Departamento de Física Teórica, Atómica y Óptica,

Universidad de Valladolid, Valladolid, Spain

A. López-Miguel ( $\square)$

Redes temáticas de investigación cooperativa en

salud (Oftared), Instituto de Salud Carlos III,

Madrid, Spain

e-mail: alopezm@ioba.med.uva.es symptoms in MGD patients. Likewise, eyelid massaging and cleaning devices are also beneficial for ocular signs and symptoms; however, patients usually need more than one session to maintain the therapeutic effect. Thermal pulsation has been reported to be more efficient than other strategies, and the effects can last up to 12 months. Moreover, intense pulsed light therapy has been demonstrated to improve ocular signs and symptoms alone and in combination with other therapies. Proper counseling of clinicians considering MGD status and patient compliance will help patients to undergo the adequate technique that best suits their condition.

Keywords: Eyelid hygiene; Intense pulsed light; Meibomian gland dysfunction; Thermal pulsation 


\section{Key Summary Points}

Most of the existing commercial devices are useful for managing MGD if performed correctly.

Regular therapeutic sessions of eyelid hygiene are required to maintain the improvement in MGD after the initial one.

Several studies have showed that thermal pulsation and intense pulsed light can be the most efficient therapies in the medium and long term.

Clinicians should counsel patients based on MGD severity and treatment compliance.

\section{DIGITAL FEATURES}

This article is published with digital features to facilitate understanding of the article. To view digital features for this article go to https://doi. org/10.6084/m9.figshare.12937559.

\section{INTRODUCTION}

Meibomian gland dysfunction (MGD) is a chronic, diffuse abnormality of the meibomian glands (MG), characterized by terminal duct obstruction and changes in the glandular secretion. This anomaly may result in alterations of the tear film, symptoms of eye irritation, clinical inflammation, and ocular surface disease [1]. Its prevalence varies between 3.5\% and $19.9 \%$ in the Caucasian population, while it reaches $>60 \%$ in the Asian population [2].

MGs are sebaceous glands located in the tarsal plates of the eyelids, and their function is to release lipids and proteins to the tear film [3]. The crucial role of the MG secretion, also called meibum, is the stabilization of the tear film and the protection of the ocular surface $[4,5]$.

According to the 'International Workshop on Meibomian Gland Dysfunction' [1], MGD is classified into two categories based on the meibum: low-delivery and high-delivery states. Low-delivery states are further divided into hyposecretory and obstructive conditions, the obstructive being the most prevalent type. Obstructive MGD is characterized by chemical changes in the meibum or terminal duct obstruction. Hyposecretory MGD is defined by a reduced release of meibum without MG obstruction. A high-delivery state or hypersecretory MGD is characterized by the presence of a large volume of lipids on the lid margin [1].

MGD is the main cause of evaporative dry eye disease (DED), the most prevalent type of DED. Additionally, MGD is present in some cases of aqueous-deficiency DED [2]. DED is an ocular surface anomaly whose prevalence ranges from 5 to $50 \%$ worldwide, and it is associated with limitations in performing activities of daily life and even sometimes with depression $[6,7]$. Therefore, it is important to properly manage MGD.

Some therapies for MGD include improving the environmental humidity, increasing dietary omega-3 fatty acid intake, using artificial tears, or anti-inflammatory therapy for DED. Nevertheless, since the final goal of the treatment is to improve the flow of MG secretions [8], eyelid hygiene is the most common clinical treatment. It consists of the application of heat and a mechanical massage of the eyelids to increase meibum secretion [1]. However, traditional warm compresses need to be reheated approximately every $2 \mathrm{~min}$ to maintain the heat for a sufficient period of time (usually $10 \mathrm{~min}$ ). This limitation makes it a time-consuming therapy and hampers compliance, which result in a lack of effectiveness $[9,10]$. Considering that there is no standard recommendation for eyelid warming and it must be easily performed to increase compliance, new therapies designed for MGD management are emerging on the market.

This review aims to detail the latest commercial medical devices available for MGD management and their clinical effectiveness. In addition, each study included in this review addressing the effectiveness of any therapy has been classified in terms of level of evidence following the Scottish Intercollegiate Guideline Network (SIGN) [11]. This article is based on 
previously conducted studies and does not contain any studies with human participants or animals performed by any of the authors.

\section{WARMING EYELID DEVICES}

\section{Warming Devices}

Warming masks help to release the meibum secretion through their application on the closed eyelids. The physiological melting point of the meibum is $32^{\circ} \mathrm{C}$, but in patients with MGD, it is reported to increase up to $45^{\circ} \mathrm{C}$ because of the alteration of its chemical composition [12]. Due to the increased melting point, temperatures close to $45^{\circ} \mathrm{C}$ have been advocated for warm compress therapy [10]. Skin burns have been reported to occur after $35 \mathrm{~min}$ of continuous exposure to thermal contact of $45^{\circ} \mathrm{C}[13,14]$. Therefore, eye care practitioners usually recommend using warming devices for 5-10 min, preventing adverse effects [15].

The MGDRx EyeBag ${ }^{\circledR}$ (The Eyebag Company, Halifax, UK) is a reusable silk and cotton mask that can be heated in a microwave for $40 \mathrm{~s}$. Peak temperatures $\left(37.6{ }^{\circ} \mathrm{C}\right)$ may be reached after 2 min of its application on the external upper eyelids. After 12 min of treatment, temperatures may slightly decrease $\left(36.8^{\circ} \mathrm{C}\right)[16,17]$.

Bilkhu et al. [17] (level of evidence: II) observed that $5 \mathrm{~min}$ of the MGDRx EyeBag ${ }^{\circledR}$ application twice a day for 2 weeks was an effective and safe treatment for MGD. Moreover, the benefits could last for 6 months when subjects continued the therapy occasionally. Murphy et al. [18] (I) showed that increasing the treatment time to 10 min seemed to be equally effective. However, Ngo et al. [19] (I) found no significant changes in clinical signs after 1 month using the MGDRx EyeBag ${ }^{\circledR}$ twice a day for $10 \mathrm{~min}$.

The EyeBag ${ }^{\circledR}$ Instant (The Eyebag Company, Halifax, UK) is a single-use, disposable warm compress. It is activated by air; therefore, it starts to heat $2-3 \mathrm{~min}$ after the mask is removed from the sachet, and it can be placed on the eyelids for $10 \mathrm{~min}$ [20].

The eyeXpress ${ }^{\mathrm{TM}}$ Eye Hydration System (Holbar Medical Products, USA) is a goggle system, which provides constant but adjustable heat to the anterior surface of both eyelids. It can be applied for $15 \mathrm{~min}$ in the required number of sessions [21].

The TearCare ${ }^{\circledR}$ System (Sight Sciences, USA) is an electrothermal controller that heats both eyelids to $41-45^{\circ} \mathrm{C}$ by adjusting them with a flexible, single-use material called iLid $^{\mathrm{TM}}$. The system encourages meibum expression through normal blinking during the treatment and through the subsequent manual MG expression-the set includes a disposable EXPRESS ${ }^{\mathrm{TM}}$ Forceps to perform the manoeuvre. Badawi et al. $[22,23]$ performed a clinical trial (I) evaluating the effectiveness of the TearCare ${ }^{\circledR}$ System and the MGDRx EyeBag ${ }^{\circledR}$ in two different groups of MGD patients. While one group underwent the TearCare $^{\circledR}$ for $12 \mathrm{~min}$ and subsequent MG expression, the other group self-applied $5 \mathrm{~min}$ of daily therapy with EyeBag ${ }^{\circledR}$ for 4 weeks. The TearCare ${ }^{\circledR}$ group showed a higher improvement in signs, including MG scores, and symptoms. Additionally, the effects lasted for 6 months, and no adverse events were reported.

The MiBo Thermoflo ${ }^{\circledR}$ (Mibo Medical Group, USA) consists of a tactile power console and a wired metal eye pad. The eye pad is heated (temperature not reported) and applied on the closed eyelids along with an ultrasound gel. There is only one case report (III) indicating that an increase in the temperature of the inner surface of the eyelids was not found after 12 min of the MiBoFlo eye pad application [24]. Therefore, further studies to prove the effectiveness of this device are required.

The EyeGiene $^{\circledR}$ Insta-Warmth System ${ }^{\mathrm{TM}}$ (Eyedetec Medical, USA) works by placing the Warming Wafers inside the mask, without heating them in the microwave. It produces heat from a chemical reaction in each wafer. Some studies compared this device with the MGDRx EyeBag ${ }^{\circledR}$. Wang et al. [25] (I) showed that clinical signs improved after the application of both therapies. Both treatments transferred their peak temperatures to the eyelids in $3 \mathrm{~min}$, although they were slightly lower in the EyeGiene $^{\circledR}$ than in the EyeBag ${ }^{\circledR}$. Furthermore, Wang et al. [26] (III) found that the warming effect of the EyeBag ${ }^{\circledR}$ was more prolonged. 
Therefore, the EyeBag ${ }^{\circledR}$ would be more effective for severe cases of MGD.

\section{Warming and Humidity Devices}

These devices also soften the meibum to increase its release by applying moist heat to the eyelids. Although it remains unclear, it was hypothesized that moist warming devices might be less effective than dry warming devices because of the cooling that follows the rapid heat evaporation in the case of moist devices [27].

The BRUDER Moist Heat Eye Compress (Bruder Healthcare, USA) is a reusable mask that absorbs water molecules from the air and releases them as moist heat. The device might maintain $54^{\circ} \mathrm{C}$ during the first $3 \mathrm{~min}$, and this temperature may slowly decrease, reaching $45^{\circ} \mathrm{C}$ after $12 \mathrm{~min}$. The contact of this high temperature mask with the eyelid skin could burn it. Therefore, clinicians and patients must proceed with caution [15]. The upper outer eyelids may reach the peak temperature $\left(40.1^{\circ} \mathrm{C}\right.$ ) after $2 \mathrm{~min}$ of treatment. Then, the heat may remain stable and decrease to $37.9^{\circ} \mathrm{C}$ after 12 min [16] Tichenor et al. [28] (I) compared the application of the BRUDER Compress once versus twice a day. Although an improvement in MG scores and symptoms was observed for both treatment regimens, DED symptoms decreased more when applying the compress once a day. Nonetheless, these results were attributed to the higher compliance observed in the once-a-day group.

The Eye-ssential ${ }^{\circledR}$ Mask (Thera Pearl, USA) produces warmth when the pearls inside the mask absorb, hold and deliver the heat acquired in the microwave. The mask reaches its peak temperature $\left(38.7^{\circ} \mathrm{C}\right)$ after $3 \mathrm{~min}$ and decreases to $37.9^{\circ} \mathrm{C}$ after $12 \mathrm{~min}$ [16].

The Blephasteam ${ }^{\circledR}$ (Théa Laboratories, France) is a goggle system that produces moist warm air and heats the eyelids through the condensation of water vapor. The melted meibum secretion is favoured by the normal blinking of the patients during the treatment. Temperatures recorded in the outer upper eyelids were between $37.4{ }^{\circ} \mathrm{C}$ and $40.0^{\circ} \mathrm{C}$ at the end of the treatment, while in the lower ones they were between $37.8^{\circ} \mathrm{C}$ and $38.4{ }^{\circ} \mathrm{C}[27,29]$.

Two studies (III) suggested that Blephasteam ${ }^{\circledR}$ might be a safe and effective therapy for MGD because DED symptoms and MG function improved after 21 days of treatment $[30,31]$. Ocular symptoms and clinical signs, except the conjunctival redness score, may achieve a higher improvement after Blephasteam $^{\circledR}$ than after warm compresses (III) [32]. However, in another study (I), signs improved equally in both therapies [33]. Nonetheless, Blephasteam ${ }^{\circledR}$ may be useful for subjects who find warm compresses ineffective (III) [34].

\section{Warming and Massaging Devices}

These devices apply heat to the eyelids to liquefy the meibum and then apply a mechanical pressure to deliver the meibum to the ocular surface.

The LipiFlow ${ }^{\circledR}$ system (Johnson \& Johnson Vision, USA) applies heat $\left(42.5^{\circ} \mathrm{C}\right)$ and simultaneous pulsated pressure to the inner upper and lower eyelids for $12 \mathrm{~min}$. The device consists of an eyelid warmer that applies the heat and an eye cup that applies the pressure through an inflatable air bladder [35].

Regarding its effectiveness, a retrospective case series study (III) showed that symptoms, MG function, lipid layer thickness (LLT), partial blink rate, and tear break-up time (BUT) improved 4 and 12 weeks after the treatment [36].

Some studies compared LipiFlow ${ }^{\circledR}$ with other MGD management strategies. Almost all of the studies comparing the LipiFlow $^{\circledR}$ with traditional eyelid hygiene (I and III) found an improvement in symptoms in the LipiFlow ${ }^{\circledR}$ group [37-40]. Only two studies (III) found an improvement in signs, such as $\mathrm{MG}$ secretion and BUT [39, 41]. Other authors compared LipiFlow $^{\circledR}$ with other medical devices, such as Tauber et al. [42] (I), who compared LipiFlow ${ }^{\circledR}$ with iLux ${ }^{\circledR}$ and did not find differences between the two treatments. Another study (II) reported that one single LipiFlow $^{\circledR}$ session was more effective in decreasing DED symptoms 
compared to 3 months of oral doxycycline [43]. Finally, Yeo et al. [44] (I) showed a significant reduction in the tear evaporation rate after 4 and 12 weeks of LipiFlow ${ }^{\circledR}$ treatment, in contrast to EyeGiene ${ }^{\circledR}$ and Blephasteam ${ }^{\circledR}$.

It was also reported that the LipiFlow ${ }^{\circledR}$ system produced successful results in patients with other conditions such as Sjögren syndrome (III) [45], dry eye after laser correction surgery (III) [41], and symptomatic contact lens wearers (I) [46].

Concerning the treatment duration, Greiner et al. $[47,48]$ conducted a study (III) with different follow-up periods. While the MG score, BUT, and symptoms improved at 9 and 12 months compared to baseline, the improvement was only sustained in the MG score and symptoms after 3 years [49]. The improvement in MG score and symptoms after 12 months agreed with the results of Blackie et al. [50] (I). In addition, Finis et al. [51] (III) also reported an improvement in ocular signs 6 months after treatment, such as LLT, the number of lid-parallel conjunctival folds, and bulbar conjunctival redness.

Several authors have tried to predict the success of the LipiFlow ${ }^{\circledR}$ treatment based on different parameters. Satjawatcharaphong et al. [52] (III) suggested that it depended on gender, DED symptoms, and non-invasive tear break-up time (NIBUT). However, another study (III) proposed that patients with lower tear production and higher ocular surface staining and osmolarity could also respond positively to the LipiFlow $^{\circledR}$ treatment [53]. The discrepancies between both studies could result from the different follow-up times. In the first study, it ranged between 21 and 84 days, while in the second one, it ranged between 30 and 40 days.

\section{MASSAGING EYELID DEVICES}

These devices facilitate the mechanical release of meibum, which has to be performed manually in conventional eyelid hygiene.

The Eyepeace eyelid massage device (Eyepeace, UK) is a self-administered silicone device for massaging the eyelids to improve meibum expression. A study (I) compared the efficacy of this device with manual eyelid massage [54]. After 2 weeks of treatment, the increase in LLT was greater in the eyes treated with the Eyepeace.

\section{CLEANING DEVICES}

These devices remove the bacterial biofilm, debris, and scurf present in the MG ducts, which could occlude them and therefore prevent meibum delivery.

The MG probing consists of the insertion of probes of different sizes in the MG ducts to dilate them and permit the subsequent meibum expression. It requires the eye to be anesthetized [55]. MG probing has been found to decrease DED symptoms 1 and 6 months after the treatment (III) [56]. Sik Sarman et al. [57] (III) treated patients using a modified cannula to reduce pain and bleeding. After the procedure, patients were prescribed antibiotics, corticosteroids, artificial tears, and eyelid massage. Most of the patients had severe MGD and required more than one session. After 3 months, BUT, conjunctival hyperaemia, eyelid margin vascularity, and DED symptoms decreased.

The NuLids (NuSight Medical, USA) is a home-use device that has a disposable silicone tip that massages the eyelids to remove biofilm and scurf [58].

The BlephEx (Blephex LLC, USA) is a handheld device for removing bacterial biofilm and debris from the eyelid [59, 60]. Murphy et al. [59] (III) studied the effectiveness of one session of BlephEx and the subsequent nightly application of OcuSoft Lid Scrub Plus foam on patients with Demodex folliculorum blepharitis. They showed that the symptomatology and the quantity of Demodex folliculorum decreased 2 and 4 weeks after the treatment. Epstein et al. [60] (I) evaluated the effectiveness of the Blephex at the beginning of the study and after 1 month in patients with Demodex blepharitis. In addition, some of the patients used terpinen-4ol eyelid scrubs twice daily for 2 months, while others used sham scrubs. The Demodex level decreased after 2 months in patients who used terpinen-4-ol, while it decreased after 1 and 2 months in patients who used sham scrubs. 
However, no changes in ocular symptoms were found. Regarding the ocular signs, patients who used sham scrubs worsened tear production and improved blepharitis signs and the ease of MG expression after 1 and 2 months.

\section{LIGHT-BASED DEVICES}

These devices apply light directly on the skin near the eyelids to treat MGD.

The intense pulsed light (IPL) devices are high-intensity, non-coherent, and non-laser light sources ranging from 500 to $1200 \mathrm{~nm}$ [61]. Patients are fitted with safety goggles covering both eyes during the treatment. The skin treatment area requires an ultrasound gel. Light pulses are applied into the cheek skin, near the lower eyelids. However, one study (I) evaluated the technique applying pulses directly into the upper eyelids [62]. A higher improvement in MG secretion function was found in the lower eyelids than in the upper eyelids. This was attributed to the smaller tear meniscus present in the upper eyelids, which contains fewer inflammatory proteins.

The number of light pulses required to improve MGD has been addressed in the clinical trial of Xue et al. [63] (I). They reported that applying five light pulses instead of four seemed to achieve higher and earlier improvements in clinical signs and DED symptoms.

One of the proposed mechanisms of IPL to improve MGD is the reduction of the bacterial load of the eyelid margin that could alter meibum secretion or obstruct MG ducts $[64,65]$. Xue et al. [63] (I) observed an inhibition of $\mathrm{Co}$ rynebacterium macginleyi growth after IPL treatment, although the effect was not observed in all the bacterial species evaluated. Conversely, Albietz et al. [66] (III) found no short-term changes in the eyelid margin colony counts cultured after IPL treatment. Another proposed mechanism is that IPL may increase the skin temperature and the heat could be absorbed by haemoglobin to eliminate the superficial blood vessels, especially when they are large [67]. The MG inflammation would be reduced by the removal of these blood vessels [68] and also because of photomodulation. According to the studies by Liu et al. [69] and Piyacomn et al. [70] (I), this process would reduce some inflammatory mediators such as interleukin (IL)-17A, IL6 , or IL-1Ra.

Two commercial IPL devices are widely used for MGD treatment: the E > Eye system (ESWIN, France), also called Intense Regulated Pulsed Light (IRPL), and the M22 system (Lumenis, Israel), also called Optimal Pulse Technology $\left(\mathrm{OPT}^{\mathrm{TM}}\right)$. There are some differences between both devices such as the treatment schedule. The $\mathrm{E}>$ Eye system is usually applied in three or four sessions, performed on days 1 , 15,45 , and $75[63,70,71]$, while the M22 system is usually applied in three sessions, separated by 3 or 4 weeks $[62,71,72]$. The spot size is $15 \times 40 \mathrm{~mm}$ in $\mathrm{E}>$ Eye and $15 \times 35 \mathrm{~mm}$ in the M22, and the cooling system is Airflow in the $\mathrm{E}>$ Eye and ChillTip ${ }^{\mathrm{TM}}$ Contact in the M22. These differences might be the reason why $\mathrm{Wu}$ et al. [71] (I) found discrepant results when comparing both devices. They found that the MG secretion function and tear film quality improved more after the M22 than after the $\mathrm{E}>$ Eye treatment.

Regarding the efficacy, some studies assessed IPL treatment alone. Jiang et al. [73] (III) observed an improvement in symptoms, BUT, conjunctival injection, and $\mathrm{MG}$ score from baseline to day 45. However, no differences were found between days 75 and 45 , suggesting that two sessions were enough to reduce the signs and symptoms of MGD. Vigo et al. [74] (III) also performed follow-up visits on day 1, 15, and 45. They found an improvement in NIBUT, LLT, and osmolarity and suggested that patients with lower BUT responded better to the treatment. Finally, Yurtasser et al. [75] (III) found an improvement in symptoms and NIBUT at 1 month and an improvement in symptoms, NIBUT, MG dropout, and corneal staining in the mild and moderate MG atrophy groups, lasting up to 12 months. No improvement was observed in patients with severe MG atrophy. However, another study (II) compared IPL with eyelid hygiene and found that although both groups improved in symptoms, BUT, and MG score; the IPL group also improved in conjunctival staining [76]. 
Several studies evaluated the IPL treatment along with other treatments. Piyacomn et al. [70] (I) observed a higher and faster improvement in the MG function in patients who combined conventional eyelid hygiene and IPL than in those patients who performed hygiene alone. Huang et al. [72] (I) compared IPL with intraductal MG probing. They reported that the combination of both methods was more effective than separately in improving symptoms, BUT, meibum grade, and telangiectasias. IPL alone was more suitable for relieving intraductal inflammation, while MG probing was better for patients with severe MG obstruction or MG scarring. Some studies combined IPL treatment with MG expression. While Toyos et al. [77] (II) only found an improvement in symptoms and BUT, Dell et al. [78] (III) also observed improvements in MG score and corneal staining. However, Arita et al. [79] conducted a randomized clinical trial (I) comparing a combined therapy and MG expression alone. They found an improvement in the symptoms, NIBUT, BUT, and MG score in both therapies. However, the improvement was higher after the combined therapy, and this group also improved the LLT and corneal staining.

There is a lack of agreement in the IPL treatment protocol. The number of sessions varies among three [74, 76], four [73, 77, 78], and eight [79], and the period between sessions can fluctuate between 15 [73, 74, 77], 21 [78, 79] and 30 [76, 77] days. Finally, the number of flashes is not standardized, $4-5$ being the most frequent $[73-75,80]$, although other authors double the flashes or apply even more [78, 79].

\section{MASSAGING AND LIGHT-BASED DEVICES}

These devices combine the application of pressure to the eyelids along with the light-based therapeutic effect to facilitate the release of meibum to the ocular surface.

The iLux $^{\circledR}$ (Alcon, USA) is a handheld device that applies light-based heat and compression to the eyelids. An inner pad slips behind the eyelid and an outer pad is pressed against the outer surface of the eyelid [58]. As mentioned above, a clinical trial (I) compared the effectiveness of LipiFlow ${ }^{\circledR}$ and iLux ${ }^{\circledR}$, without finding differences [42].

\section{CONCLUSION}

New therapies for MGD management are continuously becoming commercially available, which help clinicians and patients to better cope with the anomaly. There are several warming and humidity devices as well as eyelid massaging and cleaning devices that have showed improvement of MGD. However, treatment sessions must be performed regularly to maintain the therapeutic effect. Other instruments based on thermal pulsation and intense pulsed light technology have also demonstrated their ability to improve the MGD status for a longer time, and even in only one session, in case of thermal pulsation. The wide variety of commercial devices can allow clinicians to adequately counsel patients based on the MGD severity and therapeutic compliance.

\section{ACKNOWLEDGEMENTS}

Funding. No funding or sponsorship was received for this study or publication of this article.

Authorship. All named authors meet the International Committee of Medical Journal Editors (ICMJE) criteria for authorship for this article, take responsibility for the integrity of the work as a whole, and have given their approval for this version to be published.

Disclosures. Laura Valencia-Nieto, Andrea Novo-Diez, Marta Blanco-Vázquez, and Alberto López-Miguel do not have any commercial or proprietary interest in any product or company mentioned throughout the manuscript.

Compliance with Ethics Guidelines. This article is based on previously conducted studies and does not contain any studies with human 
participants or animals performed by any of the authors.

Open Access. This article is licensed under a Creative Commons Attribution-NonCommercial 4.0 International License, which permits any non-commercial use, sharing, adaptation, distribution and reproduction in any medium or format, as long as you give appropriate credit to the original author(s) and the source, provide a link to the Creative Commons licence, and indicate if changes were made. The images or other third party material in this article are included in the article's Creative Commons licence, unless indicated otherwise in a credit line to the material. If material is not included in the article's Creative Commons licence and your intended use is not permitted by statutory regulation or exceeds the permitted use, you will need to obtain permission directly from the copyright holder. To view a copy of this licence, visit http://creativecommons.org/licenses/by$\mathrm{nc} / 4.0 /$.

\section{REFERENCES}

1. Nelson JD, Shimazaki J, Benitez-del-Castillo JM, et al. The International Workshop on Meibomian Gland Dysfunction: report of the definition and classification subcommittee. Investig Ophthalmol Vis Sci. 2011;52(4):1930-7.

2. Schaumberg DA, Nichols JJ, Papas EB, Tong L, Uchino M, Nichols KK. The International Workshop on Meibomian Gland Dysfunction: report of the subcommittee on the epidemiology of, and associated risk factors for. MGD Investig Ophthalmol Vis Sci. 2011;52(4):1994-2005.

3. Knop E, Knop N, Millar T, Obata H, Sullivan DA. The International Workshop on Meibomian Gland Dysfunction: report of the subcommittee on anatomy, physiology, and pathophysiology of the meibomian gland. Investig Opthalmol Vis Sci. 2011;52(4):1938.

4. Green-Church KB, Butovich I, Willcox M, et al. The International Workshop on Meibomian Gland Dysfunction: report of the subcommittee on tear film lipids and lipid-protein interactions in health and disease. Investig Opthalmol Vis Sci. 2011;52(4): 1979.
5. Butovich IA, Millar TJ, Ham BM. Understanding and analyzing meibomian lipids-a review. Curr Eye Res. 2008;33(5-6):405-20.

6. Craig JP, Nichols KK, Nichols JJ, et al. TFOS DEWS II definition and classification report. Ocul Surf. 2017;15:276-83.

7. Stapleton F, Alves M, Bunya VY, et al. TFOS DEWS II epidemiology report. Ocul Surf. 2017;15(3):334-65.

8. Yan X, Qiao J. Emerging treatment options for meibomian gland dysfunction. Clin Ophthalmol. 2013;7:1797-803.

9. Freedman HL, Preston KL. Heat retention in varieties of warm compresses: a comparison between warm soaks, hard-boiled eggs and the re-heater. Ophthalmic Surg. 1989;20(12):846-8.

10. Blackie CA, Solomon JD, Greiner JV, Holmes M, Korb DR. Inner eyelid surface temperature as a function of warm compress methodology. Optom Vis Sci. 2008;85(8):675-83.

11. Square G. Scottish Intercollegiate Guidelines Network SIGN 50. A guideline developer's handbook. SIGN, Edinburgh;2008.

12. Bron AJ, Tiffany JM, Gouveia SM, Yokoi N, Voon LW. Functional aspects of the tear film lipid layer. Exp Eye Res. 2004;78(3):347-60.

13. Moritz AR, Henriques FC. Studies of thermal injury: II. The relative importance of time and surface temperature in the causation of cutaneous burns. Am J Pathol. 1947;23(5):695-720.

14. Despa F, Orgill DP, Neuwalder J, Lee RC. The relative thermal stability of tissue macromolecules and cellular structure in burn injury. Burns. 2005;31(5): 568-77.

15. Lacroix Z, Léger S, Bitton E. Ex vivo heat retention of different eyelid warming masks. Contact Lens Anter Eye. 2015;38(3):152-6.

16. Bitton E, Lacroix Z, Léger S. In-vivo heat retention comparison of eyelid warming masks. Contact Lens Anter Eye. 2016;39(4):311-5.

17. Bilkhu PS, Naroo SA, Wolffsohn JS. Effect of a commercially available warm compress on eyelid temperature and tear film in healthy eyes. Optom Vis Sci. 2014;91(2):163-70.

18. Murphy O, O'Dwyer V, Lloyd-Mckernan A. The efficacy of warm compresses in the treatment of meibomian gland dysfunction and demodex folliculorum blepharitis. Curr Eye Res. 2019;45(5): 563-75. 
19. Ngo W, Srinivasan S, Jones L. An eyelid warming device for the management of meibomian gland dysfunction. J Optom. 2019;12(2):120-30.

20. The EyeBag Company ${ }^{\circledR} .2020$. What is the EyeBag ${ }^{\circledR}$ ? Available from: https://www.eyebagcompany.com/ pages/what-is-the-eyebag

21. Beye. eyeXpress eye hydration system. 2020 Available from: https://www.beye.com/product/ eyexpress-eye-hydration-system

22. Badawi D. A novel system, TearCare ${ }^{\circledR}$, for the treatment of the signs and symptoms of dry eye disease. Clin Ophthalmol. 2018;12:683-94.

23. Badawi D. TearCare ${ }^{\circledR}$ system extension study: Evaluation of the safety, effectiveness, and durability through 12 months of a second TearCare ${ }^{\circledR}$ treatment on subjects with dry eye disease. Clin Ophthalmol. 2019;13:189-98.

24. Kenrick CJJ, Alloo SSS. The limitation of applying heat to the external lid surface: a case of recalcitrant meibomian gland dysfunction. Case Rep Ophthalmol. 2017;8(1):7-12.

25. Wang MTM, Jaitley Z, Lord SM, Craig JP. Comparison of self-applied heat therapy for meibomian gland dysfunction. Optom Vis Sci. 2015;92(9): 321-6.

26. Wang MTM, Gokul A, Craig JP. Temperature profiles of patient-applied eyelid warming therapies. Contact Lens Anter Eye. 2015;38(6):430-4.

27. Murakami DK, Blackie CA, Korb DR. All warm compresses are not equally efficacious. Optom Vis Sci. 2015;92(9):327-33.

28. Tichenor AA, Cox SM, Ziemanski JF, et al. Effect of the Bruder moist heat eye compress on contact lens discomfort in contact lens wearers: an open-label randomized clinical trial. Contact Lens Anter Eye. 2019;42(6):625-32.

29. Purslow C. Evaluation of the ocular tolerance of a novel eyelid-warming device used for meibomian gland dysfunction. Contact Lens Anter Eye. 2013;36(5):226-31.

30. Benitez-del-Castillo JM, Kaercher T, Mansour K, Wylegala E, Dua H. Evaluation of the efficacy, safety, and acceptability of an eyelid warming device for the treatment of meibomian gland dysfunction. Clin Ophthalmol. 2014;8:2019-27.

31. Doan S, Chiambaretta F, Baudouin C. Evaluation of an eyelid warming device (Blephasteam ${ }^{\circledR}$ ) for the management of ocular surface diseases in France: the ESPOIR study. J Fr Ophtalmol. 2014;37(10): 763-72.
32. Pult H, Riede-Pult BH, Purslow C. A comparison of an eyelid-warming device to traditional compress therapy. Optom Vis Sci. 2012;89(7):1035-41.

33. Sim HS, Petznick A, Barbier S, et al. A randomized, controlled treatment trial of eyelid-warming therapies in meibomian gland dysfunction. Ophthalmol Ther. 2014;3(1-2):37-48.

34. Villani E, Garoli E, Canton V, Pichi F, Nucci P, Ratiglia R. Evaluation of a novel eyelid-warming device in meibomian gland dysfunction unresponsive to traditional warm compress treatment: an in vivo confocal study. Int Ophthalmol. 2015;35(3): $319-23$.

35. Korb DR, Blackie CA. Restoration of meibomian gland functionality with novel thermodynamic treatment device-a case report. Cornea. 2010;29(8):930-3.

36. Liang Q, Liu H, Guo Y, et al. Clinical evaluation of a thermodynamic treatment system for meibomian gland dysfunction. Zhonghua Yan Ke Za Zhi. 2015;51(12):924-31.

37. Friedland BR, Fleming CP, Blackie CA, Korb DR. A novel thermodynamic treatment for meibomian gland dysfunction. Curr Eye Res. 2011;36(2): 79-877.

38. Finis D, Hayajneh J, König C, Borrelli M, Schrader S, Geerling G. Evaluation of an automated thermodynamic treatment $\left(\right.$ Lipiflow $\left.^{\circledR}\right)$ system for meibomian gland dysfunction: a prospective, randomized, observer-masked trial. Ocul Surf. 2014;12(2):146-54.

39. Zhao Y, Xie J, Li J, et al. Evaluation of monocular treatment for meibomian gland dysfunction with an automated thermodynamic system in elderly chinese patients: a contralateral eye study. J Ophthalmol. 2016;27:1-8.

40. Zhao Y, Veerappan A, Yeo S, et al. Clinical trial of thermal pulsation (LipiFlow) in meibomian gland dysfunction with preteatment meibography. Eye Contact Lens. 2016;42(6):339-46.

41. Schallhorn CS, Schallhorn JM, Hannan S, Schallhorn SC. Effectiveness of an eyelid thermal pulsation procedure to treat recalcitrant dry eye symptoms after laser vision correction. J Refract Surg. 2017;33(1):30-6.

42. Tauber J, Owen J, Bloomenstein M, Hovanesian J, Bullimore MA. Comparison of the iLUX and the lipiflow for the treatment of meibomian gland dysfunction and symptoms: a randomized clinical trial. Clin Ophthalmol. 2020;14:405-18. 
43. Hagen KB, Bedi R, Blackie CA, Christenson-Akagi KJ. Comparison of a single-dose vectored thermal pulsation procedure with a 3-month course of daily oral doxycycline for moderate-to-severe meibomian gland dysfunction. Clin Ophthalmol. 2018;12: 161-8.

44. Yeo S, Tan JH, Acharya UR, Sudarshan VK, Tong L. Longitudinal changes in tear evaporation rates after eyelid warming therapies in meibomian gland dysfunction. Investig Ophthalmol Vis Sci. 2016;57(4):1974-81.

45. Epitropoulos AT, Goslin K, Bedi R, Blackie CA. Meibomian gland dysfunction patients with novel Sjögren's syndrome biomarkers benefit significantly from a single vectored thermal pulsation procedure: a retrospective analysis. Clin Ophthalmol. 2017;11: 701-6.

46. Blackie CA, Coleman CA, Nichols KK, et al. Asingle vectored thermal pulsation treatment for meibomian gland dysfunction increases mean comfortable contact lens wearing time by approximately 4 hours per day. Clin Ophthalmol. 2018;12:169-83.

47. Greiner JV. A single LipiFlow ${ }^{\circledR}$ thermal pulsation system treatment improves meibomian gland function and reduces dry eye symptoms for 9 months. Curr Eye Res. 2012;37(4):272-8.

48. Greiner JV. Long-term (12-month) improvement in meibomian gland function and reduced dry eye symptoms with a single thermal pulsation treatment. Clin Exp Ophthalmol. 2013;41(6):524-30.

49. Greiner JV. Long-term (3 year) effects of a single thermal pulsation system treatment on meibomian gland function and dry eye symptoms. Eye and Contact Lens. 2016;42(2):99-107 (Lippincott Williams and Wilkins).

50. Blackie CA, Coleman CA, Holland EJ. The sustained effect (12 months) of a single-dose vectored thermal pulsation procedure for meibomian gland dysfunction and evaporative dry eye. Clin Ophthalmol. 2016;10:1385-96.

51. Finis D, König C, Hayajneh J, Borrelli M, Schrader S, Geerling G. Six-month effects of a thermodynamic treatment for MGD and implications of meibomian gland atrophy. Cornea. 2014;33(12):1265-70.

52. Satjawatcharaphong P, Ge S, Lin MC. Clinical outcomes associated with thermal pulsation system treatment. Optom Vis Sci. 2015;92(9):334-41.

53. Gibbons A, Waren D, Yesilirmak N, et al. Ocular surface parameters predicting patient satisfaction after a single vectored thermal pulsation procedure for management of symptomatic meibomian gland dysfunction. Cornea. 2017;36(6):679-83.
54. Wang MTM, Feng J, Wong J, Turnbull PR, Craig JP. Randomised trial of the clinical utility of an eyelid massage device for the management of meibomian gland dysfunction. Contact Lens Anter Eye. 2019;42(6):620-4.

55. Maskin SL, Alluri S. Meibography guided intraductal meibomian gland probing using real-time infrared video feed. Br J Ophthalmol. 2020

56. Wladis EJ. Intraductal meibomian gland probing in the management of ocular rosacea. Ophthalmic Plastic and Reconstructive Surgery. Ophthalmic Plast Reconstr Surg. 2012;28:416-8.

57. Sarman ZS, Cucen B, Yuksel N, Cengiz A, Caglar Y. Effectiveness of intraductal meibomian gland probing for obstructive meibomian gland dysfunction. Cornea. 2016;35(6):721-4.

58. Devices for Treating The Meibomian Glands. 2020 Available from: https://www. reviewofophthalmology.com/article/devices-fortreating-the-meibomian-glands

59. Murphy O, O’Dwyer V, Lloyd-McKernan A. The efficacy of tea tree face wash, 1, 2-octanediol and microblepharoexfoliation in treating demodex folliculorum blepharitis. Contact Lens Anter Eye. 2018;41(1):77-82.

60. Epstein IJ, Rosenberg E, Stuber R, Choi MB, Donnenfeld ED, Perry HD. Double-masked and unmasked prospective study of terpinen-4-ol lid scrubs with microblepharoexfoliation for the treatment of demodex blepharitis. Cornea. 2020;39(4): 408-16.

61. Li D, Bin LS, Cheng B. Intense pulsed light: from the past to the future. Photomed Laser Surg. 2016;34:435-47 (Mary Ann Liebert Inc.).

62. Rong B, Tang $\mathrm{Y}, \mathrm{Tu} \mathrm{P}$, et al. Intense pulsed light applied directly on eyelids combined with meibomian gland expression to treat meibomian gland dysfunction. Photomed Laser Surg. 2018;36(6): 326-32.

63. Xue AL, Wang MTM, Ormonde SE, Craig JP. Randomised double-masked placebo-controlled trial of the cumulative treatment efficacy profile of intense pulsed light therapy for meibomian gland dysfunction: intense pulsed light therapy for meibomian gland dysfunction. Ocul Surf. 2020;18(2): 286-97.

64. Geerling G, Tauber J, Baudouin C, et al. The international workshop on meibomian gland dysfunction: report of the subcommittee on management and treatment of meibomian gland dysfunction. Investig Opthalmol Vis Sci. 2011;52(4):2050. 
65. Kirn T. Intense pulsed light eradicates Demodex mites. Ski Allerg News. 2002;33(1):37.

66. Albietz JM, Schmid KL. Intense pulsed light treatment and meibomian gland expression for moderate to advanced meibomian gland dysfunction. Clin Exp Optom. 2018;101(1):23-33.

67. Bäumler W, Vural E, Landthaler M, Muzzi F, Shafirstein G. The effects of intense pulsed light (IPL) on blood vessels investigated by mathematical modeling. Lasers Surg Med. 2007;39(2):132-9.

68. Papageorgiou P, Clayton W, Norwood S, Chopra S, Rustin M. Treatment of rosacea with intense pulsed light: significant improvement and long-lasting results. Br J Dermatol. 2008;159(3):628-32.

69. Liu R, Rong B, Tu P, et al. Analysis of cytokine levels in tears and clinical correlations after intense pulsed light treating meibomian gland dysfunction. Am J Ophthalmol. 2017;183:81-90.

70. Piyacomn Y, Kasetsuwan N, Reinprayoon U, Satitpitakul V, Tesapirat L. Efficacy and safety of intense pulsed light in patients with meibomian gland dysfunction-a randomized, double-masked, shamcontrolled clinical trial. Sham Controll Clin Trial Cornea. 2020;39(3):325-32.

71. Wu Y, Li J, Hu M, et al. Comparison of two intense pulsed light patterns for treating patients with meibomian gland dysfunction. Int Ophthalmol. 2020;40(7):1695-705.

72. Huang X, Qin Q, Wang L, Zheng J, Lin L, Jin X. Clinical results of intraductal meibomian gland probing combined with intense pulsed light in treating patients with refractory obstructive meibomian gland dysfunction: a randomized controlled trial. BMC Ophthalmol. 2019;19(1):211.

73. Jiang X, Lv H, Song $H$ et al. Evaluation of the safety and effectiveness of intense pulsed light in the treatment of meibomian gland dysfunction. J Ophthalmol. 2016

74. Vigo L, Taroni L, Bernabei F, et al. Ocular surface workup in patients with meibomian gland dysfunction treated with intense regulated pulsed light. Diagnostics. 2019;9(4):147.

75. Yurttaser Ocak S, Karakus S, Ocak OB, et al. Intense pulse light therapy treatment for refractory dry eye disease due to meibomian gland dysfunction. Int Ophthalmol. 2020;8:1-7.

76. Yin Y, Liu N, Gong L, Song N. Changes in the meibomian gland after exposure to intense pulsed light in meibomian gland dysfunction (MGD) patients. Curr Eye Res. 2018;43(3):308-13.

77. Toyos R, Toyos M, Willcox J, Mulliniks H, Hoover J. Evaluation of the safety and efficacy of intense pulsed light treatment with meibomian gland expression of the upper eyelids for dry eye disease. Photobiomodulation Photomed Laser Surg. 2019;37(9):527-31.

78. Dell SJ, Gaster RN, Barbarino SC, Cunningham D. Prospective evaluation of intense pulsed light and meibomian gland expression efficacy on relieving signs and symptoms of dry eye disease due to meibomian gland dysfunction. Clin Ophthalmol. 2017;11:817-27.

79. Arita R, Fukuoka S, Morishige N. Therapeutic efficacy of intense pulsed light in patients with refractory meibomian gland dysfunction. Ocul Surf. 2019;17(1):104-10.

80. Stonecipher K, Abell TG, Chotiner B, Chotiner E, Potvin R. Combined low level light therapy and intense pulsed light therapy for the treatment of meibomian gland dysfunction. Clin Ophthalmol. 2019;13:993-9. 